\title{
Captura híbrida negativa em displasia intraepitelial isolada de córnea
}

\author{
Negative hybrid capture in a single \\ intraepithelial corneal dysplasia
}

Luiz Fernando Taranta Martin ${ }^{1}$, Marco Antonio Bonini Filho², Alexandre Nakao Odashiro ${ }^{3}$, Lizabel Gemperli, Daniela Barbosa Gemperli ${ }^{5}$, Eduardo Melani Rocha ${ }^{6}$, Jayter Silva de Paula ${ }^{7}$

\section{RESUMO}

As displasias intraepiteliais de córnea correspondem a lesões de baixo risco de malignidade, dentro do espectro das neoplasias intraepiteliais da superfície ocular. Essas displasias se apresentam como áreas leucoplásicas e têm como um dos principais fatores de risco o papilomavírus humano (HPV). No presente trabalho, os autores descrevem um caso de displasia intraepitelial isolada de córnea, tratada através de excisão cirúrgica, com confirmação histológica e resultado negativo de hibridização de DNA para HPV.

Descritores: Carcinoma in situ/cirurgia; Doença da córnea/patologia Neoplasias oculares; Neoplasias da conjuntiva; Infecções por papillomavirus/diagnóstico; Relatos de casos

\footnotetext{
'Doutor, Chefe do Setor de Glaucoma do Instituto da Saúde Ocular de Mato Grosso do Sul - Campo Grande (MS), Brasil;

${ }^{2}$ Pós-graduando (Doutorado) pelo Departamento de Oftalmologia, Otorrinolaringologia e Cirurgia de Cabeça e Pescoço da Faculdade de Medicina de Ribeirão Preto da Universidade de São Paulo - USP - Ribeirão Preto (SP), Brasil;

${ }^{3}$ Doutor, Responsável pelo Setor de Patologia Ocular do Laboratório de Anatomia Patológica e Citopatologia - Campo Grande (MS), Brasil;

${ }^{4}$ Médica, Diretora do Instituto de Saúde Ocular do Mato Grosso do Sul - Campo Grande (MS), Brasil;

${ }^{5}$ Médica, Chefe do Setor de Córnea do Instituto da Saúde Ocular de Mato Grosso do Sul - Campo Grande (MS), Brasil;

${ }^{6}$ Professor do Departamento de Oftalmologia, Otorrinolaringologia e Cirurgia de Cabeça e Pescoço da Faculdade de Medicina de Ribeirão Preto da Universidade de São Paulo - USP - Ribeirão Preto (SP), Brasil;

${ }^{7}$ Professor do Departamento de Oftalmologia, Otorrinolaringologia e Cirurgia de Cabeça e Pescoço da Faculdade de Medicina de Ribeirão Preto da Universidade de São Paulo - USP - Ribeirão Preto (SP), Brasil.
}

Instituição: Faculdade de Medicina de Ribeirão Preto - USP

Recebido para publicação em: 7/12/2009 - Aceito para publicação em 1/3/2010 


\section{INTRODUÇÃO}

A s neoplasias intraepiteliais de córnea (NIC) e conjuntiva compreendem o espectro mais benigno da neoplasia intraepitelial da superfície ocular $^{(1-4)}$. São lesões com baixo risco de malignidade e de lenta progressão ${ }^{(2,4)}$, que têm como fatores de risco o papilomavírus humano (HPV), exposição a radiação ultravioleta e, possivelmente, infecção pelo $\operatorname{HIV}^{(2,5)}$.

As lesões podem se apresentar como um tecido opaco de aspecto membranoso sobre a superfície corneana ou como leucoplasias gelatinosas, planas ou elevadas. São, geralmente, encontradas em áreas de ex$\operatorname{posição~}^{(1,5)}$.

O sistema de captura híbrida em microplaca é um método de biologia molecular, composto por uma solução hibridizadora, que utiliza anticorpos específicos para captura de híbridos de RNA-DNA, com amplificação de sinal. Todos os testes de captura híbrida são, ao mesmo tempo, qualitativos e quantitativos. O método é capaz de detectar os tipos mais comuns de HPV, que representam $95 \%$ dos vírus que infectam o trato anogenital ${ }^{(6-8)}$.

Os autores relatam um caso de displasia intraepitelial corneana tratado exclusivamente com excisão cirúrgica da lesão, com confirmação histológica e resultado negativo de captura híbrida para HPV.

\section{Relato de caso}

Paciente do sexo masculino, caucasiano, 61 anos, procurou avaliação oftalmológica de rotina, queixandose de baixa acuidade visual à direita, progressiva, nos últimos 6 meses. Sem outras queixas oftalmológicas. Ao exame apresentava acuidade visual corrigida de 0,3 no olho direito (OD) e 1,0 no olho esquerdo (OE). Ao exame de biomicroscopia, foram observadas duas lesões epiteliais corneanas em placa no OD, com aspecto leucoplásico acinzentado, sem vascularização e sem acometimento limbar visível (figura 1A e 1B). No OE, não se identificou alteração. $\mathrm{O}$ exame fundoscópico apresentava-se normal em ambos os olhos.

O diagnóstico presumido foi de displasia intraepitelial corneana e o tratamento indicado foi a excisão cirúrgica completa das duas lesões, com margem de segurança de $1 \mathrm{~mm}$ e preservação de tecido limbar. O material retirado foi submetido a estudo histopatológico e captura híbrida para HPV.Foram prescritos colírios de antibiótico de 3/3 horas e lubrificante ocular em gel, de 6/6 horas, por 7 dias. Após 6 dias, a córnea apresentava-se totalmente epitelizada, com le-

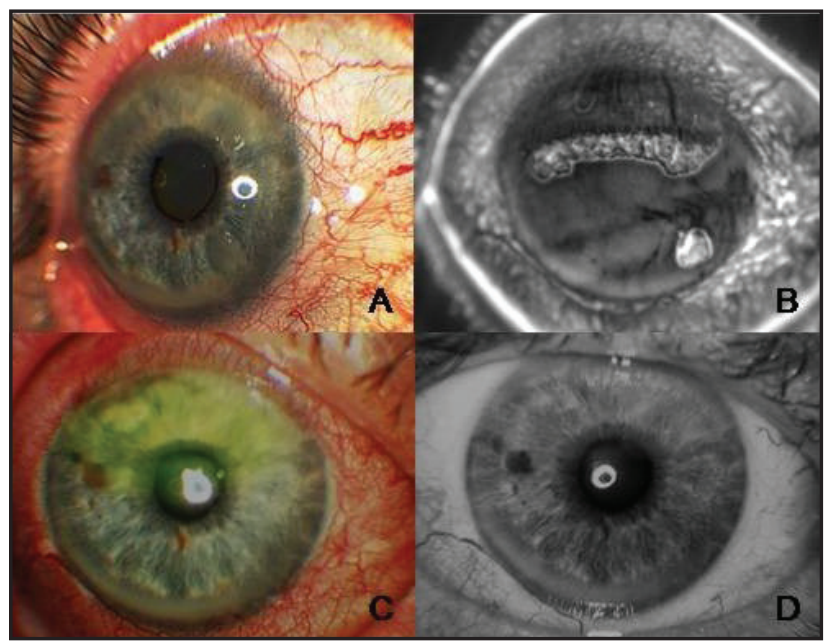

Figura 1: Fotografia em lâmpada de fenda do paciente nos diversos momentos de exame. Pré-operatório: $A$ - observar aspecto acinzentado das lesões, em região perilimbar superior e inferior; $B$ fotografia red free da córnea, favorecendo delimitação das lesões. Pós-operatório: $C$ - área da lesão corada por colírio de fluoresceína no primeiro dia após o procedimento; $D$ - Aspecto totalmente epitelizado, sem sinais de recidiva, em fotografia red free, após 12 meses

ves irregularidades de espessura nas áreas abordadas.

As secções histológicas revelaram fragmentos de epitélio corneano apresentando proliferação das células epiteliais, com moderada atipia, evidenciada por hipercromasia nuclear e aumento da relação núcleocitoplasma, com presença de pleomorfismos. As células atípicas acometiam cerca de $2 / 3$ da profundidade epitelial e não havia sinais de invasão do estroma corneano (figura 2B). Um raspado da córnea foi também realizado imediatamente após a retirada da lesão. O material foi colhido com uma escova (cotonete) do kit coletor de captura híbrida e transportado no meio coletor, de acordo com as especificações do fabricante (captura híbrida em microplaca - Digene ${ }^{\circledR}$, Gaithersburg, Maryland,EUA). A captura híbrida em microplaca para HPV teve resultado negativo em duas amostras. O seguimento do paciente foi feito com consultas oftalmológicas bimestrais durante 12 meses. Na última consulta, o paciente apresentava acuidade visual corrigida de 0,7 em OD e 1,0 em OE. À biomicroscopia, observava-se leve irregularidade de espessura corneana na região superior, com epitelização completa e ausência de sinais de recidiva.

\section{DısCUSSÃO}

O tratamento primário da neoplasia intraepitelial compreende as excisões cirúrgicas, associadas, em muitos casos, à crioterapia ${ }^{(3-6)}$. Em casos de acometimento 

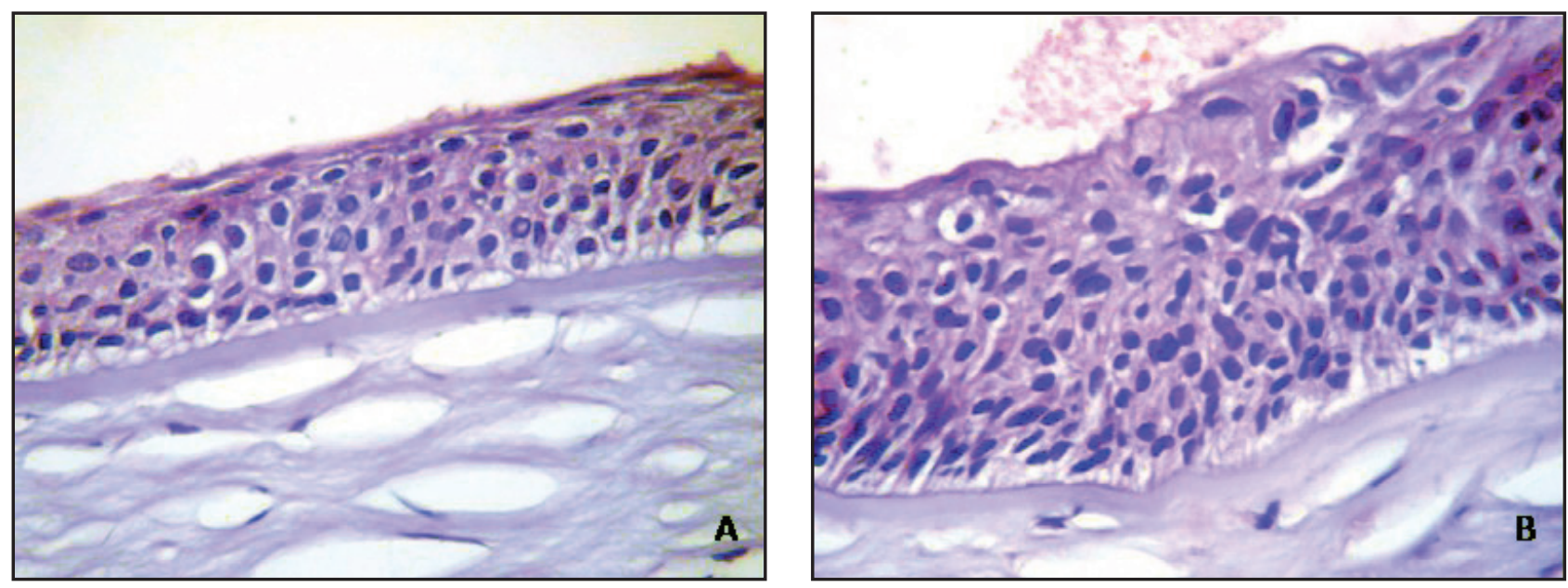

Figura 2: $A$. Fotomicrografia de epitélio normal do paciente, em área fora da região de lesão; $B$. Fotomicrografia da NIC, observandose epitélio corneano com os $2 / 3$ basais, apresentando hiperplasia, ceratócitos com aumento de volume, hipercromasia e irregularidade nuclear, sugerindo efeito citopático do HPV (H\&E, 400x).

conjuntival, a técnica de Moh deve ser preferencialmente utilizada para a redução do risco de recorrência ${ }^{(5)}$. Os antineoplásicos têm sido utilizados como tratamento adjunto, com o objetivo de reduzir o alto índice de recorrência ${ }^{(4,5,9,10-13)}$ e de evitar sucessivas abordagens cirúrgicas, prevenindo fibrose conjuntival e insuficiência limbar ${ }^{(3,13)}$.

Apesar de a excisão cirúrgica ainda ser o tratamento de escolha para a neoplasia intraepitelial, a recorrência das lesões pode chegar a $56 \%$, dependendo da abordagem empregada ${ }^{(3-5)}$. Em função disso, os agentes antineoplásicos têm sido cada vez mais utilizados como terapia adjunta ${ }^{(5,9,13)}$. Entre esses, se destacam a mitomicina C (MMC) $)^{(13)}$, o 5-fluouracil $(5-\mathrm{FU})^{(9)}$ e o interferon $2 b^{(4,5,9)}$, que mostraram-se eficazes na redução das taxas de recorrência e são usados atualmente inclusive como monoterapia em alguns casos ${ }^{(8,10-12)}$.

Apesar dos resultados promissores, os antineoplásicos não são isentos de efeitos colaterais. Além disso, não há consenso sobre a concentração atóxica ideal e o número de ciclos necessários para o tratamento das displasias intraepiteliais de superfície $\operatorname{ocular}^{(6)}$. No caso relatado, a lesão foi removida em toda a sua extensão. As margens de segurança apresentaram-se livres de displasias no estudo histopatológico, o que evitou a necessidade de posterior ampliação para tecido limbar e conjuntival. Foi também dispensado o tratamento adjunto com antineoplásicos, uma vez que não houve indícios de acometimento limbar ao exame biomicroscópico ou de recidiva nos doze primeiros meses de seguimento.

A frequência de detecção do HPV nas displasias intraepiteliais da superfície ocular varia consideravelmente, dependendo da metodologia utilizada ${ }^{(7,10-12,14-18)}$. A captura híbrida parece ser o método mais empregado, detectando os 18 principais tipos do vírus, incluindo os que causam lesão de alto grau e carcinoma ${ }^{(8,19,20)}$.

A falha na detecção do HPV pela captura híbrida pode ocorrer em decorrência de alguns fatores. A lesão pode não ser causada pelo HPV, mas ser associada a outra causa, como a radiação ultravioleta; o número de partículas virais para a detecção pelo método pode ser insuficiente; e o tipo do HPV pode não ser passível de detecção pelo método.

Apesar de o método de detecção do HPV por hibridização aqui empregado ser comercialmente disponível e amplamente utilizado no meio médico, ele foi desenvolvido para raspados genitais ${ }^{(19)}$. Alguns trabalhos na literatura demonstraram a presença de HPV na conjuntiva através de outros métodos de detecção, como reação em cadeia da polimerase (PCR) e a hibridização por dot blot ${ }^{(7)}$. Porém, tais métodos possuem custo elevado e não são rotineiramente empregados no país, restringindo-se a uso para pesquisa.

A identificação do HPV nessas lesões pela técnica de captura híbrida é uma ferramenta de baixo custo que pode acrescentar informações importantes na condução de casos de NIC. A ausência de positividade para HPV pode correlacionar-se com menores taxas de recidiva após a exérese das lesões.

No presente relato, a ampla quantidade de material coletado e a tipicidade dos achados histológicos sugerem que o método de captura híbrida por microplaca não foi capaz de detectar o HPV, apontando para a pos- 
sível presença de um tipo não-detectável do vírus.

Serão necessários, contudo, novos estudos com emprego da técnica aqui proposta, no sentido de se verificar os níveis de sensibilidade e especificidade deste teste, haja vista a importância da detecção do HPV nesse tipo de lesão da superfície ocular e o baixo custo do presente método.

\section{AbStract}

Cornea intraepithelial dysplasias are lesions with low risk of malignancy within the spectrum of intraepithelial neoplasia of the ocular surface. These areas are presented as dysplasias or leukoplasias and are associated with the presence of human papillomavirus (HPV), a major risk factor. In this report, the authors describe a case of a corneal intraepithelial dysplasia treated by surgical excision, with histological confirmation and negative DNA hybridization for HPV.

Keywords: Carcinoma in situ/surgery; Córneal diseases/pathology; Eye neoplasms; Conjunctival neoplasms; Papillomavirus Infections/diagnosis; Case reports

\section{REFERÊNCIAS}

1. Lee GA, Hirst LW. Ocular surface squamous neoplasia. Surv Ophthalmol. 1995;39(6):429-50.

2. Lee GA, Williams G, Hirst LW, Green AC. Risk factors in the development of ocular surface epithelial dysplasia. Ophthalmology. 1994;101(2):360-4.

3. Tabin G, Levin S, Snibson G, Loughnan M, Taylor H. Late recurrences and the necessity for long-term follow-up in corneal and conjunctival intraepithelial neoplasia. Ophthalmology. 1997;104(3):485-92.

4. Boehm MD, Huang AJ. Treatment of recurrent corneal and conjunctival intraepithelial neoplasia with topical interferon alfa 2b. Ophthalmology. 2004;111(9):1755-61.

5. Karp CL, Moore JK, Rosa RH Jr. Treatment of conjunctival and corneal intraepithelial neoplasia with topical interferon alpha-2b. Ophthalmology. 2001;108(6):1093-8.

6. Buus DR, Tse DT, Folberg R, Buuns DR. Microscopically controlled excision of conjunctival squamous cell carcinoma. Am J Ophthalmol. 1994;117(1):97-102.

7. Palazzi MA, Erwenne CM, Villa LL. Detection of human papillomavirus in epithelial lesions of the conjunctiva. Sao Paulo Med J. 2000;118(5):125-30.

8. Weston AC, Prolla JC. Association between esophageal squamous cell carcinoma and human papillomavirus detected by Hybrid Capture II assay. Dis Esophagus. 2003;16(3):224-8.

9. Vann RR, Karp CL. Perilesional and topical interferon alfa$2 \mathrm{~b}$ for conjunctival and corneal neoplasia. Ophthalmology. 1999;106(1):91-7.
10. Heigle TJ, Stulting RD, Palay DA. Treatment of recurrent conjunctival epithelial neoplasia with topical mitomycin C. Am J Ophthalmol. 1997;124(3):397-9.

11. Frucht-Pery J, Sugar J, Baum J, Sutphin JE, Pe'er J, Savir H, et al. Mitomycin $\mathrm{C}$ treatment for conjunctival-corneal intraepithelial neoplasia: a multicenter experience. Ophthalmology. 1997;104(12):2085-93.

12. de Keizer RJ, de Wolff-Rouendaal D, van Delft JL. Topical application of 5-fluorouracil in premalignant lesions of cornea, conjunctiva and eyelid. Doc Ophthalmol. 1986;64(1):31-42.

13. Yamamoto N, Ohmura T, Suzuki H, Shirasawa H. Successful treatment with 5-fluorouracil of conjunctival intraepithelial neoplasia refractive to mitomycin-C. Ophthalmology. 2002;109(2):249-52.

14. Benevides dos Santos PJ, Borborema dos Santos CM, Rufino Mendonça R, Vieira do Carmo MA, Astofi-Filho S. Human papillomavirus type 13 infecting the conjunctiva. Diagn Microbiol Infect Dis. 2005;53(1):71-3.

15. Moubayed P, Mwakyoma H, Schneider DT. High frequency of human papillomavirus $6 / 11,16$, and 18 infections in precancerous lesions and squamous cell carcinoma of the conjunctiva in subtropical Tanzania. Am J Clin Pathol. 2004;122(6):938-43.

16. Scott IU, Karp CL, Nuovo GJ. Human papillomavirus 16 and 18 expression in conjunctival intraepithelial neoplasia. Ophthalmology. 2002;109(3):542-7.

17. Karcioglu ZA, Issa TM. Human papilloma virus in neoplastic and non-neoplastic conditions of the external eye. Br J Ophthalmol. 1997;81(7):595-8.

18. Takamura Y, Kubo E, Tsuzuki S, Akagi Y. Detection of human papillomavirus in pterygium and conjunctival papilloma by hybrid capture II and PCR assays. Eye (Lond). 2008;22(11):1442-5.

19. Petry KU, Menton S, Menton M, van Loenen-Frosch F, de Carvalho Gomes H, Holz B. Inclusion of HPV testing in routine cervical cancer screening for women above 29 years in Germany: results for 8466 patients. $\mathrm{Br} \mathrm{J}$ Cancer. 2003;88(10):1570-7.

20. Kujan O, Desai M, Sargent A, Bailey A, Turner A, Sloan P. Potential applications of oral brush cytology with liquid-based technology: results from a cohort of normal oral mucosa. Oral Oncol. 2006;42(8):810-8.

Endereço para correspondência

Prof. Dr. Jayter Silva de Paula

Departamento de Oftalmologia, Otorrinolaringologia

e Cirurgia de Cabeça e Pescoço, Hospital das

Clínicas de Ribeirão Preto, $12^{\circ}$ andar - Campus USP

Av. Bandeirantes, $\mathbf{n}^{\circ} 3900$

CEP 14049-900 - Ribeirão Preto (SP), Brasil

Tel: (16) 602-2499

Fax: (16) 602-2860

E-mail: jayterdepaula@fmrp.usp.br 